\title{
Effect of Asphalt Film Thickness on Shear Mechanical Properties of
}

\author{
Asphalt-Aggregate Interface \\ Mansheng Donga, Wei Sun ${ }^{\mathrm{a}}$, Linglin $\mathrm{Li}^{\mathrm{a}}{ }^{\mathrm{ab}, *}$, Yangming $\mathbf{G a o}^{\mathrm{b}}$

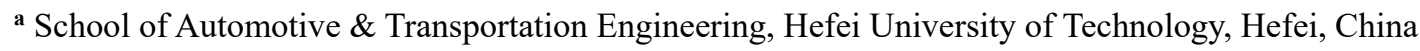 \\ b School of Engineering and Applied Science, Aston University, Birmingham, UK \\ Highlights: \\ - Developed an experimental control method of the asphalt film thickness \\ - Captured the shear behaviour of asphalt-aggregate interface under different \\ asphalt film thickness
}

- Obtained the shear failure mechanism of asphalt-aggregate interface

ABSTRACT: This paper focuses on the effect of asphalt film thickness on the shear mechanical properties of asphalt aggregate interface. Firstly, an experiment controlling the asphalt film thickness was designed to build the relationship between the asphalt film thickness and the molding load. Then, a shear test was carried out to characterize the properties of asphalt-aggregate interface under different asphalt film. The stressdisplacement curves showed two modes: single and double wave peaks. The probability relationship between the two modes and the asphalt film thickness was established. Finally, the influence of asphalt film thickness on the shear failure mechanism of asphalt-aggregate interface phase was analyzed. Results show that an experimental method for controlling the asphalt film thickness is effectively developed. When the asphalt film thickness is $23.6 \mu \mathrm{m}$ and $219 \mu \mathrm{m}$, only the single wave peak mode appears in the stress-displacement curves. Otherwise, the stress-displacement curves of comparison experiments with other thicknesses show single wave peak and double wave peak, respectively. The double peak probability is found to be related to the asphalt film thickness. The asphalt film thickness is the key point which determines the shear failure behavior of the aggregate-asphalt interface phase, such as cohesive failure or adhesion failure.

Keywords: Aggregate-asphalt Interface; Shear Test; Failure Mode; Cohesive Failure; Adhesion Failure

\footnotetext{
* Corresponding author.

E-mail address: dongms@hfut.edu.cn (Mansheng Dong),1226179867@qq.com (Wei Sun), bruceleeseu@hfut.edu.cn (Linglin Li), gaoy14@aston.ac.uk (Yangming Gao)
} 


\section{Introduction}

Asphalt pavement, as a continuous and seamless pavement, has been widely used around the world. Shear deformation can occur in the asphalt road surface due to the repeated traffic load, especially in the intersection of roads where the vehicle is frequently braked and started. Thus, the asphalt pavement performance is degraded, affecting the normal use of roads [1-3]. The deterioration of asphalt pavement performance during the life of the road is a process of damage accumulation of the internal structure of the pavement or a process of multi-scale crack initiation and propagation of the asphalt mixture inside the pavement [4].

Asphalt mixture is usually regarded as a three-phase material composed of asphalt, aggregate and void [5]. A layer of structural asphalt is formed during the mixing process of asphalt and aggregates. The mechanical properties of structural asphalt are significantly different from that of the free asphalt. As shown in Fig. 1, the asphalt mixture can be viewed as a three-phase material consisting of a reinforcing phase (aggregate), a matrix phase (asphalt), and an interfacial phase between asphalt and aggregate. The interface phase shows a complex structure with a large stress gradient, where a crack initiation is easily appeared. The mechanical properties of the interface phase have a significant impact on the overall performance of the asphalt mixture [57]. It has been reported that the failure behavior of asphalt pavement is directly related to the nature of the asphalt-aggregate interfacial zones in asphalt mixture $[9,10]$.

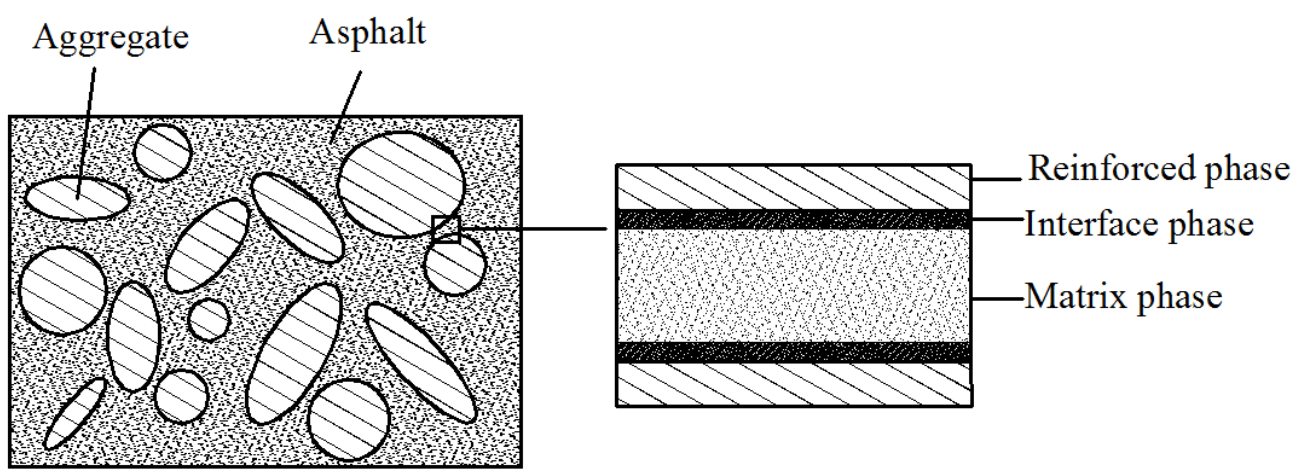

Fig.1. Asphalt mixture structure diagram

The asphalt-aggregate interfacial adhesion characteristics are complex, and related to aggregate mineralogy, adsorbed cations on the aggregate surface, specific surface area and surface free energy of the aggregate [11]. Some adhesion-based theories have been proposed for explaining the adhesion mechanism of the asphalt-aggregate interface. Based on them, the adhesion between asphalt and mineral material is mainly attributed to the intermolecular force. The surface of the mineral material is usually rough, which increases the surface e area of mineral material and improves the interfacial adhesion $[12,13]$. Electrostatic theory points out that the asphalt-aggregate interface forms a double-layer electrical layer, which produces attractive electrostatic coulomb force. The strength of interface phase comes from the interaction between the two-layer electrical 
layers $[14,15]$. The theory of surface free energy focuses on the physical and chemical adsorption between asphalt and aggregate. The adhesion of asphalt to aggregate is calculated by measuring the work of adhesion between asphalt and aggregate [16-18]. The adhesion, moisture resistance and wettability of the asphalt-aggregate system are evaluated according to the energy index of the asphalt-aggregate system [19, 11]. According to molecular orientation theory, the polarity of asphalt is the nature of adhesion. The combination film between asphalt and aggregate is formed by the orientated adsorption of asphalt surfactant to the aggregate surface. These findings provide a good theoretical basis for understanding the interaction between asphalt and aggregate under different conditions.

In addition to these adhesion-based theories, the mechanical properties of the asphaltaggregate interfacial adhesion were also experimentally investigated under tensile and shear loads [20-23]. Failure of the asphalt-aggregate interface is caused by cohesive failure (internal failure of asphalt), adhesion failure (interfacial zone failure), or the combination of them [24]. Asphalt in the asphalt mixture is presented in the form of a film. It was found that the asphalt film on the aggregate surface plays a key role in the bonding performance of the asphalt-aggregate interface, affecting the durability of asphalt mixture [25]. The asphalt film thickness is directly related to the two different failure mechanisms including adhesion failure and cohesive failure [26]. However, the influence of the asphalt film thickness on the pavement performance of asphalt mixture is usually ignored in road construction projects when the performance of asphalt mixture does not meet the requirements of the specification. Thus, it is necessary to deeply understand the effect of asphalt film thickness on the mechanical property of asphalt-aggregate interface.

The thickness control of asphalt film has always been a difficulty in studying the performance of asphalt mixtures. Cala et al [27] prepared a thin film of asphalt of 20 $\mu \mathrm{m}$ between a metallic stub and a cylindrical rock core with a controlled geometry by a modified micrometer. In the asphalt mixture design, the controlled film thickness ranges from 8 to $10 \mu \mathrm{m}$ according to the film thickness calculation method of density grading mixture. This method can only calculate the average asphalt film thickness in asphalt mixture [28-30], but does not accurately reflect the difference of asphalt film thickness in microscopic scale that is extremely important for the asphalt-aggregate interfacial durability.

The objective of this study is to investigate the influence of asphalt film thickness on the mechanical behavior of the asphalt-aggregate interface under shear loads. A new test method was designed to control the asphalt film thickness. The mechanical behavior of the asphalt-aggregate interface with different asphalt film thicknesses was experimentally investigated. The shear failure mechanisms of the asphalt-aggregate interface were analyzed based on the test results. The research scheme adopted in this study is shown in Fig.2. 


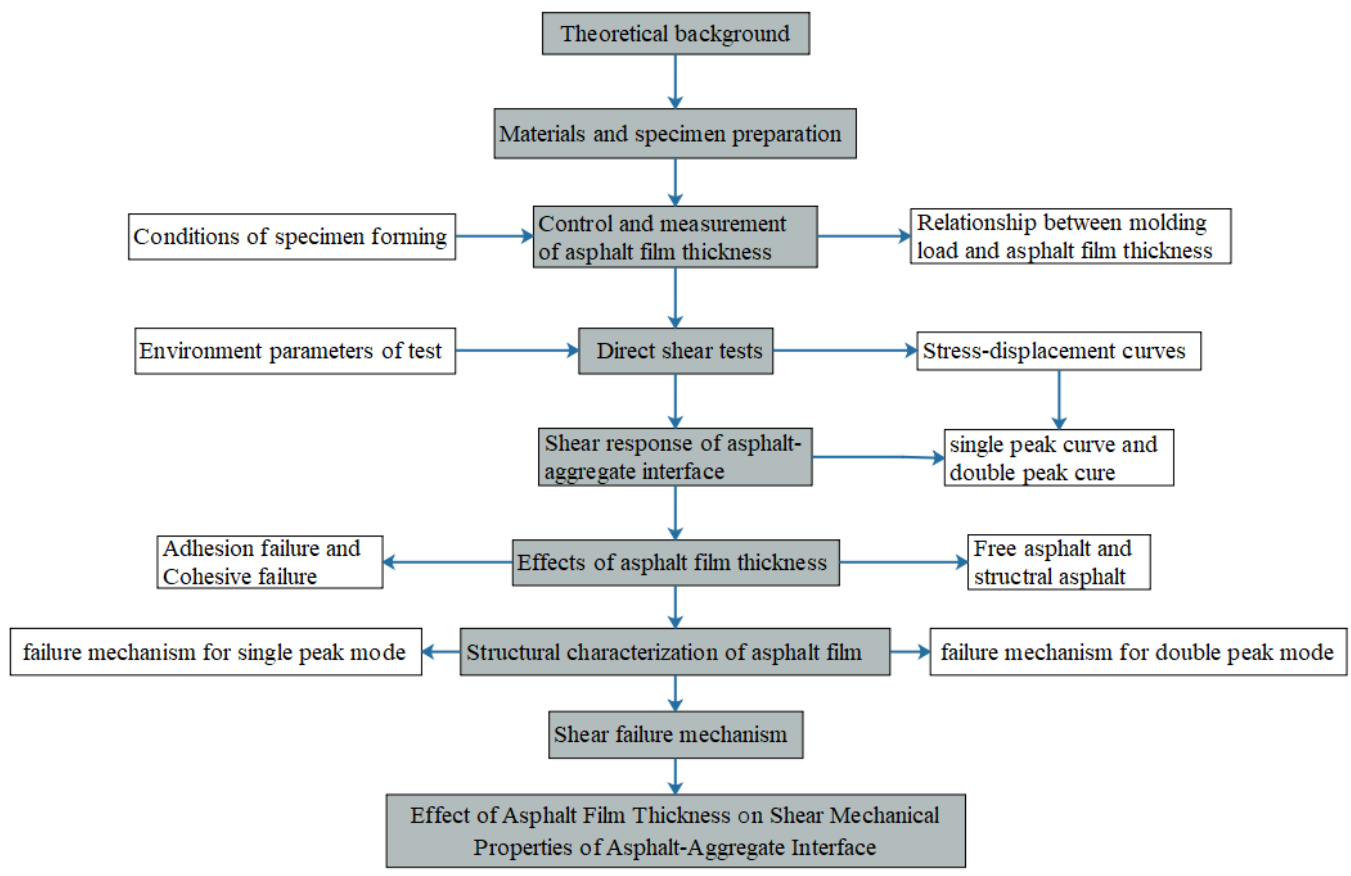

Fig.2. Research methodology adopted in this study

\section{Materials and laboratory tests}

\subsection{Materials and specimen preparation}

107 SBS modified asphalt is used in this study. The property parameters of the asphalt are shown in Table 1. The aggregate used in the test is limestone, which was obtained from Huangshan Mountain in the south of Anhui province in China, and its property parameters are presented in Table 2. Limestone is a kind of carbonate rocks with main composition of $\mathrm{CaCO}_{3}$ and the apparent relative density of $2.473 \mathrm{~g} / \mathrm{cm}^{3}$. The interface sample is designed as an aggregate-asphalt-aggregate sandwich form to simulate the basic composition unit in asphalt mixture system, as shown in Fig. 3.

Table 1. Performance indexes of SBS modified asphalt

\begin{tabular}{ccc}
\hline Test item & Test results & Technical index \\
\hline Penetration index $(0.1 \mathrm{~mm})\left(25^{\circ} \mathrm{C}, 100 \mathrm{~g}, 5 \mathrm{~s}\right)$ & 50 & $30 \sim 60$ \\
Softening point $($ ring-and-ball method $)\left({ }^{\circ} \mathrm{C}\right)$ & 81 & $\geq 60$ \\
Ductility $\left(5^{\circ} \mathrm{C}, 5 \mathrm{~cm} / \mathrm{min}\right) \quad(\mathrm{cm})$ & 24 & $\geq 20$ \\
Density $\left(15^{\circ} \mathrm{C}\right)\left(\mathrm{g} / \mathrm{cm}^{3}\right)$ & 1.027 & \\
\hline
\end{tabular}

Table 2. Technical indexes for aggregate

\begin{tabular}{lcccc}
\hline $\begin{array}{l}\text { Technical } \\
\text { indexes }\end{array}$ & $\begin{array}{c}\text { Los Angeles abrasion } \\
\text { value }(\%)\end{array}$ & $\begin{array}{c}\text { Crushing value } \\
(\%)\end{array}$ & $\begin{array}{c}\text { Water } \\
\text { absorption } \\
(\%)\end{array}$ & $\begin{array}{c}\text { Apparent } \\
\text { relative } \\
\text { density }\end{array}$ \\
\hline Test results & 11.9 & 12.1 & 0.84 & 2.473 \\
\hline
\end{tabular}




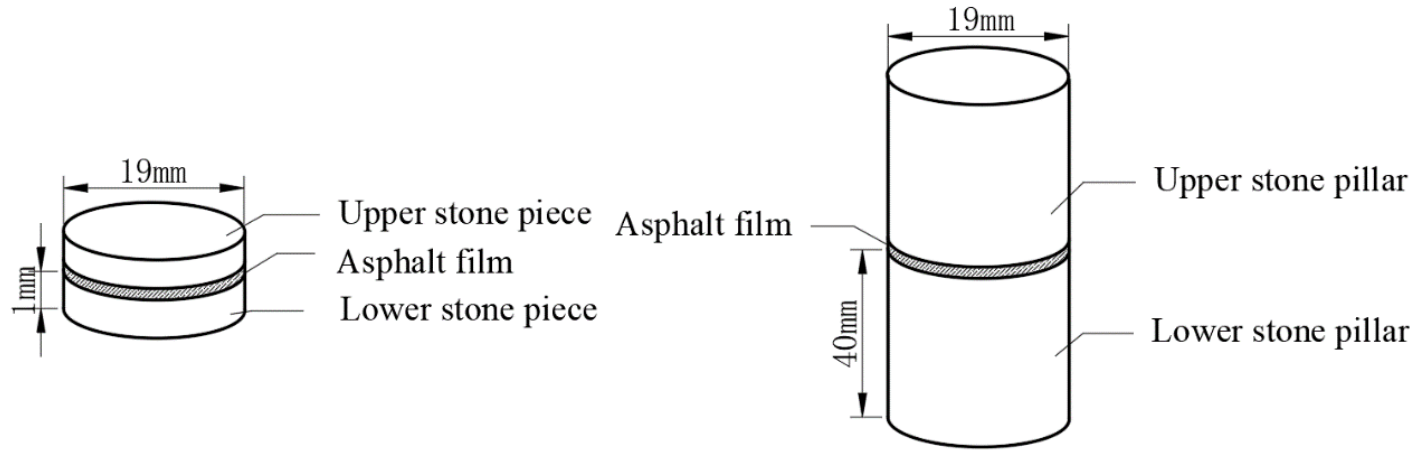

(a) Sample A

(b) Sample B

Fig. 3. Diagram of aggregate-asphalt-aggregate sample

120 The specimens shown in Fig. 3 were prepared as follows:

121 (1) A cylindrical sample with the diameter of $19 \mathrm{~mm}$ and the height of $40 \mathrm{~mm}$ was drilled from a limestone using a core-drilling machine, as shown in Fig.3 (b). The stone pillar was cut as a slice with thickness of $1 \mathrm{~mm}$ by a cutter to prepare the sample A.

(2) The roughness of the original aggregate is quite different. In order to facilitate the comparison, the sample is polished before the experiment. The surface of the stone pillar and the slices were polished with the abrasive of 120 grade SIC particles whose roughness is $37.8 \mu \mathrm{m}$. Surface roughness refers to the unevenness of small peaks and valleys on the machined surface here.

129 (3) Place the stone pillars or the stone slices in a self-made fixture shown in Fig. 4(a). The lower stone pillar or stone slice was fixed, and the upper stone pillar or stone slice can be moved up and down freely after centering to the lower stone pillar or stone slice.

132 (4) The stone pillar or stone slice and the fixture are placed in a $30{ }^{\circ} \mathrm{C}$ oven. The hot asphalt was evenly painted on the surface of the lower stone pillar or stone slice, and then the upper stone pillar or stone slice was quickly placed on the lower stone pillar or stone slice with the hot asphalt. To control the asphalt film thickness, weights were placed on the loading platform to provide vertical loads. The loading platform is shown 137 in Fig. 4(b).

138 (5) The temperature of the oven was increased to $80{ }^{\circ} \mathrm{C}$ at the rate of $4{ }^{\circ} \mathrm{C} / \mathrm{min}$, keeping 139 for 3 minutes at $80^{\circ} \mathrm{C}$.

140 (6) Remove the load, take out the test specimen, and maintain it for 24 hours at room 141 temperature of $25^{\circ} \mathrm{C}$. 


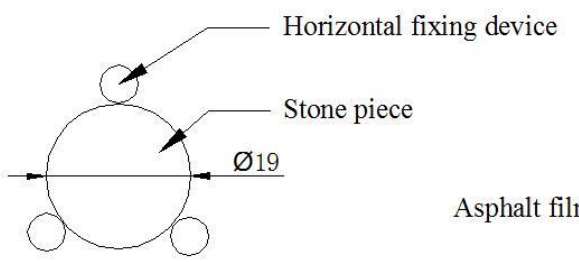

(a)Top view of fixing device for stone pieces

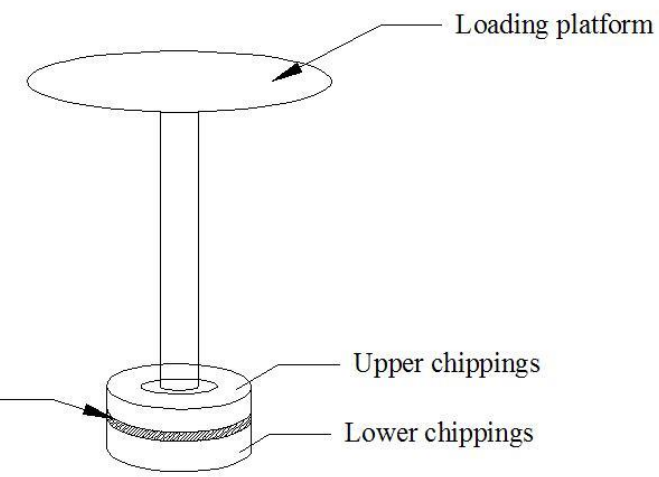

(b) Side view of loading platform for weights

Fig.4. Diagram of self-made fixture for sample preparation

\subsection{Control and measurement of asphalt film thickness}

The asphalt film thickness was controlled by applying different loads on the upper stone piece during the preparation of the sandwich specimens. The applied loads were 10.37 $\mathrm{kPa}, 27.67 \mathrm{kPa}, 47.56 \mathrm{kPa}, 61.38 \mathrm{kPa}, 90.57 \mathrm{kPa}$, and $179.76 \mathrm{kPa}$, respectively. The specimens were divided into 6 groups and each group was consist of five A type samples (shown in Fig.3a). The sample A was maintained in a temperature chamber of $25^{\circ} \mathrm{C}$ for 24 hours and then frozen in a temperature chamber of $-16^{\circ} \mathrm{C}$ for 6 hours. Then, the sample A was broken from the middle point to obtain a cross section sample of the aggregate-asphalt-aggregate. The cross section images of sandwich test piece under different molding loads were obtained by means of an scanning electron microscope (SEM) to measure the asphalt film thickness, which overcomes the difficulty of direct measurement on film thickness of the sample A. Fig. 5 shows the measurements of the asphalt film thickness between two aggregate surfaces (Sample A-1 and Sample A-2) in the sandwich samples. The thickness of the film was measured by SEM, five independent samples were selected under each load, five points were randomly measured for each sample, and the average value of over 15 points was taken as the final thickness value.

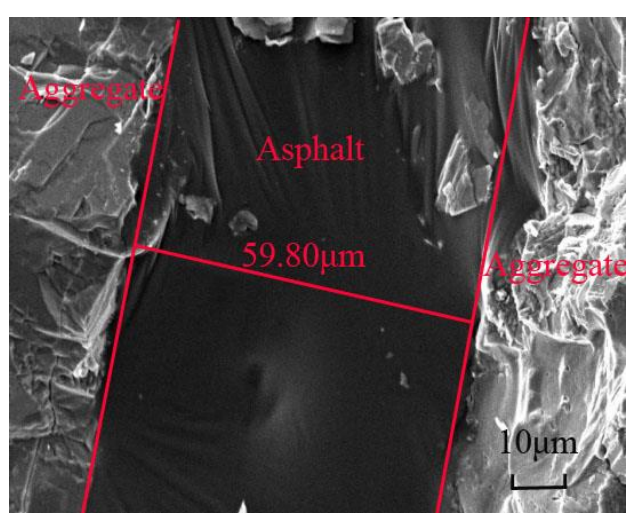

Sample A-1

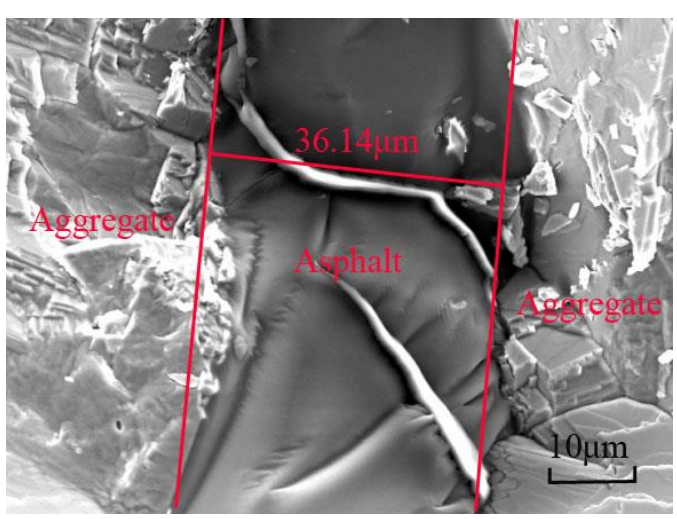

Sample A-2

Fig.4. Measurements of asphalt film thickness

The asphalt film thicknesses of all the tested samples were measured by SEM and the 
results are shown in Table 3. Asphalt film thickness with different load levels are shown in Fig. 6. The quantitative relationship between the asphalt film thickness and the load levels is fitted as follows:

$$
y=22.66+273.94 \mathrm{e}^{(-x / 30.609)}
$$

Where, $y$ is the thickness of asphalt film, $\mu \mathrm{m} ; x$ is the load level, $\mathrm{kPa}$.

It can be seen from Fig. 5 that as the molding load increases, the asphalt film thickness first decreases rapidly and then slowly approaches the thickness of structural asphalt.

Table 3. Test results of asphalt film thickness with different molding loads

\begin{tabular}{ccccccc}
\hline Group & G1 & G2 & G3 & G4 & G5 & G6 \\
\hline $\begin{array}{c}\text { thickness of Asphalt film } \\
(\mu \mathrm{m})\end{array}$ & 219.00 & 129.81 & 83.16 & 61.20 & 34.36 & 23.61 \\
\hline
\end{tabular}

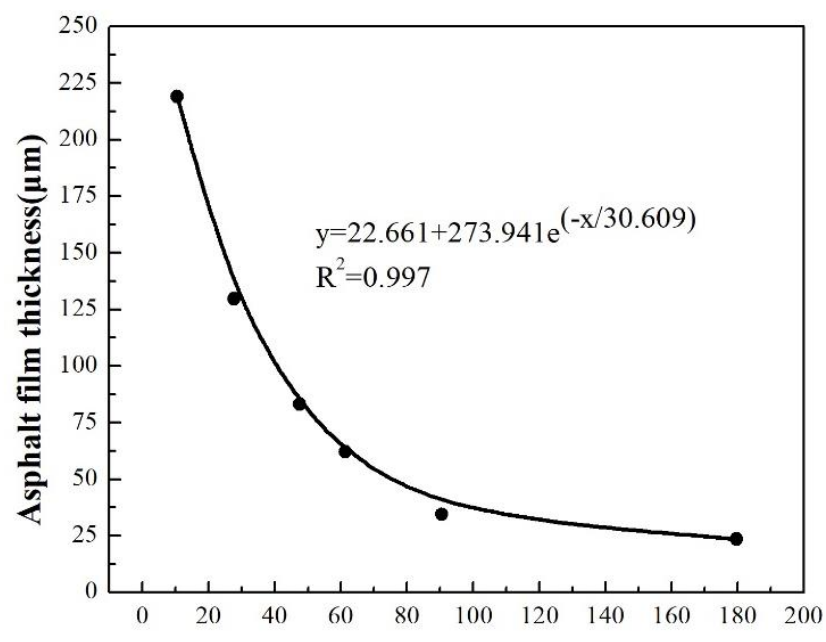

Molding load (kPa)

Fig. 6. Relationship between molding load and asphalt film thickness

\subsection{Direct shear tests of asphalt-aggregate interface}

The direct shear test was carried out using WDW-1 universal material testing machine with temperature-control chamber, which is shown in Fig.7. During the shear testing, the applied load and displacement response of the tested sandwiched specimen are recorded automatically by the microcomputer. The direct shear test would be ceased when the shear load dropped to a relatively small residual load level. The detailed experimental process can be referred to the literature [20]. Sandwich test pieces of aggregate-asphalt-aggregate were firstly prepared according to the method shown above. Then the test specimens were cured at $25^{\circ} \mathrm{C}$ for 24 hours. Before the shear test, all the samples were held in the temperature chamber at $25^{\circ} \mathrm{C}$ for one hour, and all test pieces were preheated sufficiently. The above six groups of specimens were subjected to the shear loads at the temperature of $25^{\circ} \mathrm{C}$ and the loading rate of $5 \mathrm{~mm} / \mathrm{min}$. When the shear force was reduced to $10 \mathrm{~N}$, the test stopped automatically. Twenty shear tests were carried out for each asphalt film thickness to analyze the probability of single and double peaks. 


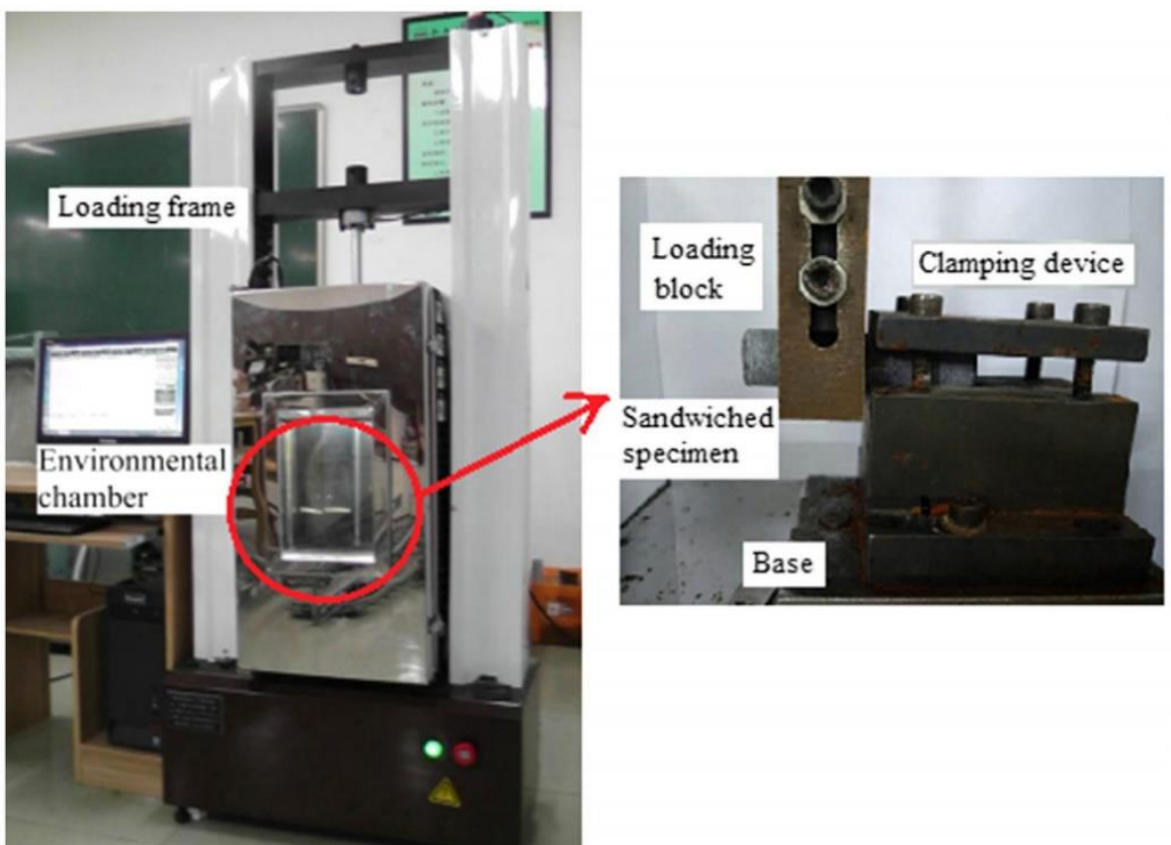

Fig.7. The direct shear test apparatus

\section{Results and discussion}

\subsection{Shear response of asphalt-aggregate interface}

Fig. 8 and Fig. 9 show the typical shear responses of the asphalt-aggregate interfaces for all the tested groups with different asphalt film thicknesses. The tested samples in Groups 1 and 6 present a single-peak stress-displacement curve. However, some samples in Group 2-5 show single-peak stress-displacement curves and the rest have double-peak stress-displacement curves. Based on the results of the direct shear tests for all the tested groups, the stress-displacement curves of the asphalt-aggregate interface under the shear loads present two different modes, which are further shown in Fig. 10. One mode is a stress-displacement curve with only one peak, called single peak mode shown in Fig. 10(a). The other mode is a stress-displacement curve with two peaks, called double peak mode shown in Fig. 10(b). It should be noted that the double peak curves were only found in tested Groups 2-5. 


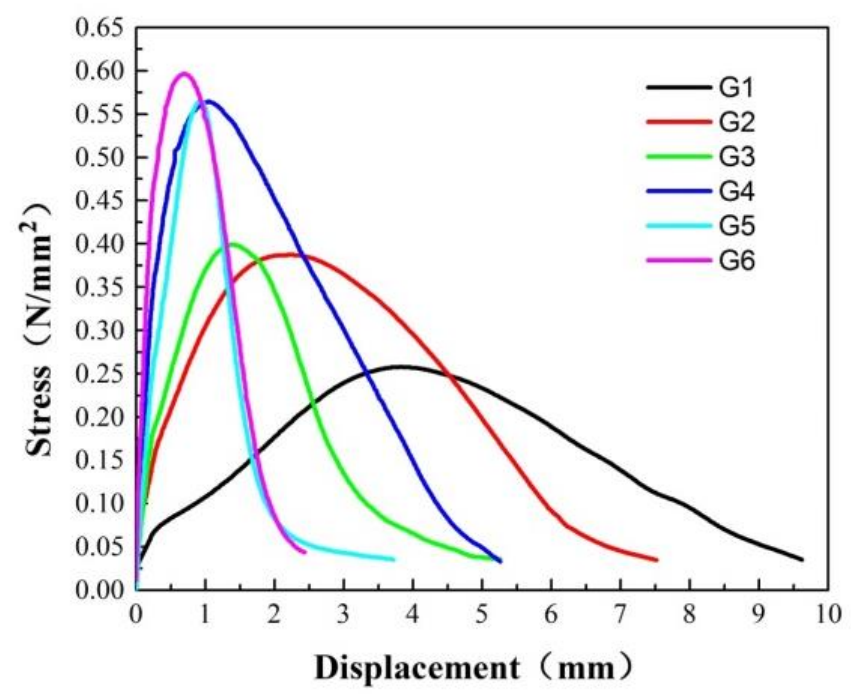

Fig.8. Typical single peak curves for stress-displacement relation of asphaltaggregate interface in each tested group

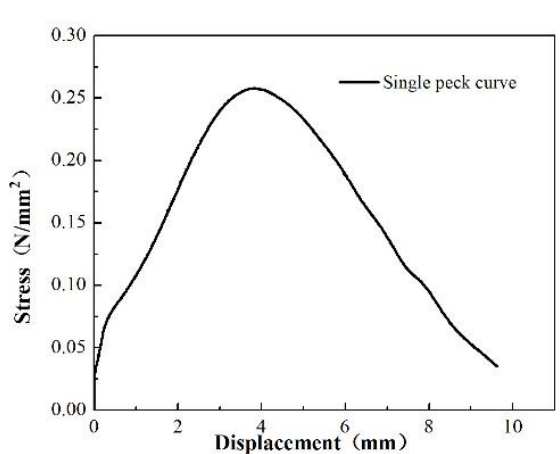

209

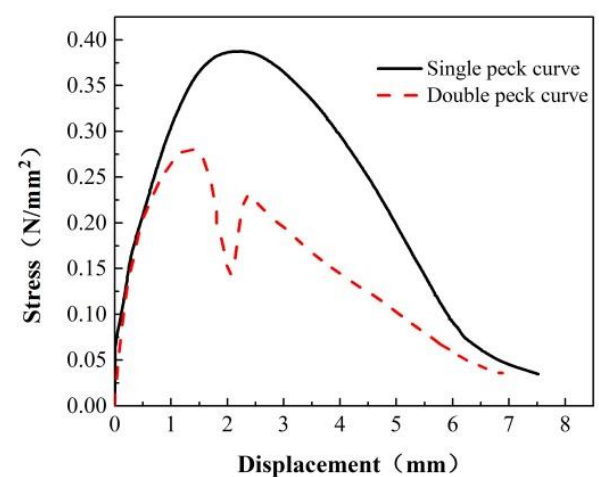

(b) Group 2
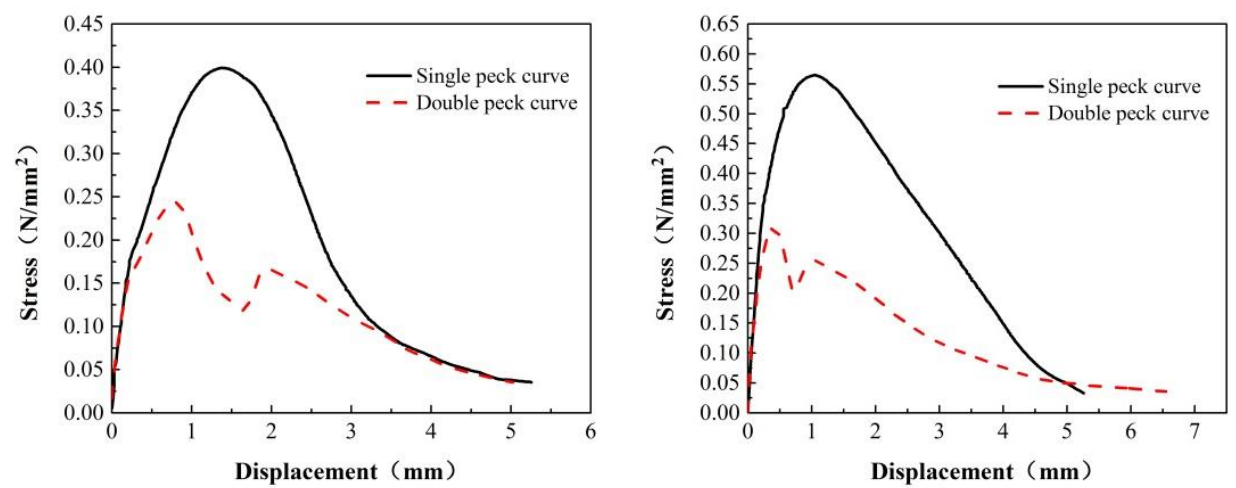

(d) Group 4 


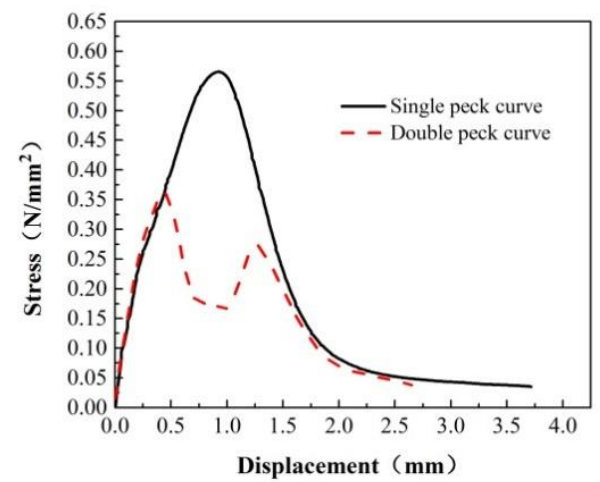

(e) Group 5

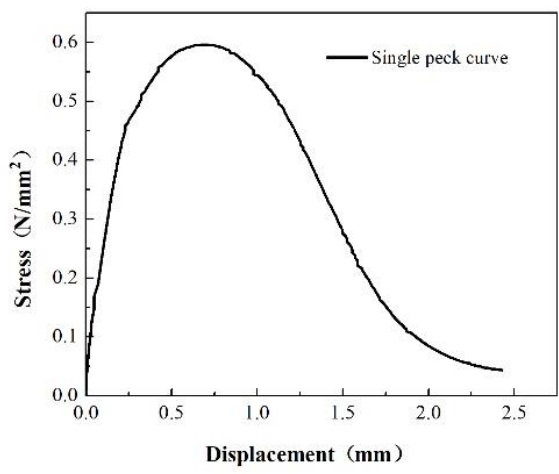

(f) Group 6

Fig.9. Typical single and double peak curves for stress-displacement relation of asphalt-aggregate interface

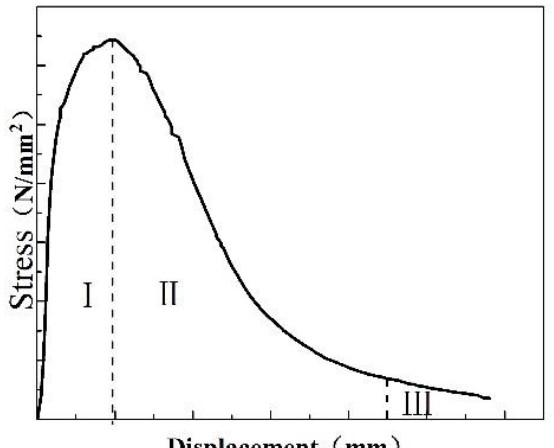

Displacement（mm

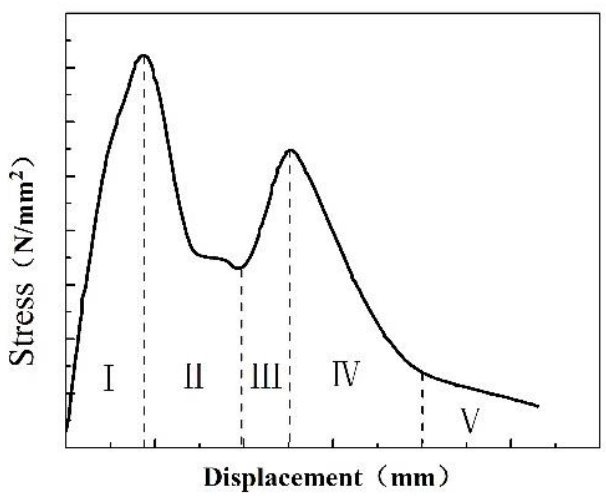

(b) Double peak curve

(a) Single peak curve

Fig.10. Stress-displacement curves of asphalt-aggregate interface under the shear loads

The single peak curve can be divided into three parts: rising zone I, falling zone II and residual zone III, as shown in Fig. 10(a). At the initial stage of the shear load, the shear stress of specimens increases rapidly and then the growth rate gradually decreases until reaches zero. At this moment, the stress increases to the peak value, which is the shear strength of the interface phase. After reaching the peak, the curve enters the falling zone II. The rate of stress reduction is first slow and then becomes fast until an inflection point occurs. Then the stress drop rate gradually decreases and finally transits to the residual zone III and the shear stress value gradually approaches zero.

The double peak curve shown in Fig. 10(b) can be divided into five parts: the first rising zone, the first falling zone, the second rising zone, the second falling zone, and the residual zone. At the initial stage of the shear load, the shear stress of interface phase increases sharply in a short time period and reaches the first stress peak. After reaching the first stress peak, the shear stress drops rapidly and enters the first falling zone until the trough. Subsequently, the shear stress goes to the second rising zone, and the slope of stress-displacement curve is first large and then becomes small, reaching the second 
stress peak. After reaching the second stress peak, it comes to the second falling zone. The linear feature of the second falling zone is similar to the falling zone of the single peak curve. Finally, the shear stress decreases slowly and gradually transits to the residual zone.

\subsection{Effects of asphalt film thickness}

The effects of asphalt film thickness on the shear mechanical response of the asphaltaggregate interfaces can be investigated based on the results of the direct shear tests for all the tested groups. The occurrence probability of the double peak curve (DPC) is calculated in every tested group and the probability of DPC with different asphalt film thicknesses is shown in Fig.11. It is found from Fig. 11 that the modes of the stressdisplacement curve are directly related to the asphalt film thickness between the aggregates. When the asphalt film thickness is $23 \mu \mathrm{m}$ (Group 6), the stressdisplacement curves of the tested samples show single peak mode and the double peak curve does not occur. As the asphalt film thickness increases, the occurrence probability of DPC increases and then reaches a maximum value of $40 \%$ when the asphalt film thickness is $83 \mu \mathrm{m}$ (Group 3). After that, the probability of DPC decreases as the asphalt film thickness further increases. When the asphalt film thickness reaches $219 \mu \mathrm{m}$ (Group 1), DPC does not appear. It can be concluded that the asphalt film thickness significantly affects the probability of occurrence of double peak in the stressdisplacement curves of the asphalt-aggregate interface under the direct shear loads. As the asphalt film thickness increases, the probability of occurrence of double peak gradually increases from zero to the maximum value, and then gradually decreases back to zero.

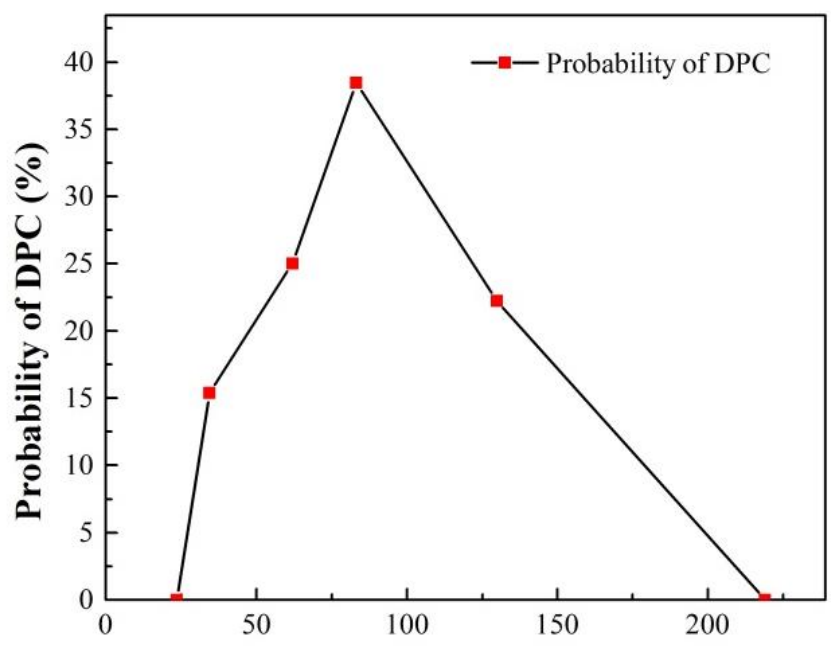

Asphalt film thickness $(\mu \mathrm{m})$

Fig. 11. Relationship between occurrence probability of double peak and asphalt film thickness

Fig. 12 and Fig. 13 show the peak stress and the corresponding displacement with different asphalt film thicknesses in single peak mode, respectively. When the asphalt film thickness is $219 \mu \mathrm{m}$ (Group 1, single-peak mode), the mean peak stress is 0.26 $\mathrm{MPa}$ and the displacement corresponding to the peak stress is $3.10 \mathrm{~mm}$. When the 
asphalt film thickness decreases to $130 \mu \mathrm{m}$ (Group 2), $83 \mu \mathrm{m}$ (Group 3), $62 \mu \mathrm{m}$ (Group 4) and $34 \mu \mathrm{m}$ (Group 5), the mean peak stress is $0.37 \mathrm{MPa}, 0.39 \mathrm{MPa}, 0.43 \mathrm{MPa}$ or 0.45 $\mathrm{MPa}$, and the corresponding displacement is $1.94 \mathrm{~mm}, 1.64 \mathrm{~mm}, 1.37 \mathrm{~mm}$ or $1.04 \mathrm{~mm}$, respectively. At these four film thicknesses, the stress-displacement curves show single and double peak mode. When the asphalt film thickness is $23 \mu \mathrm{m}$ (Group 6, single-peak mode), the mean peak stress is $0.61 \mathrm{MPa}$ and the displacement corresponding to the peak stress is $0.8 \mathrm{~mm}$. It can be concluded that, as the asphalt film thickness increases, the peak tress deceases but the corresponding displacement increases. There is a nonlinear or linear relationship between the peak stress or the corresponding displacement and the asphalt thickness for the asphalt-aggregate interface.

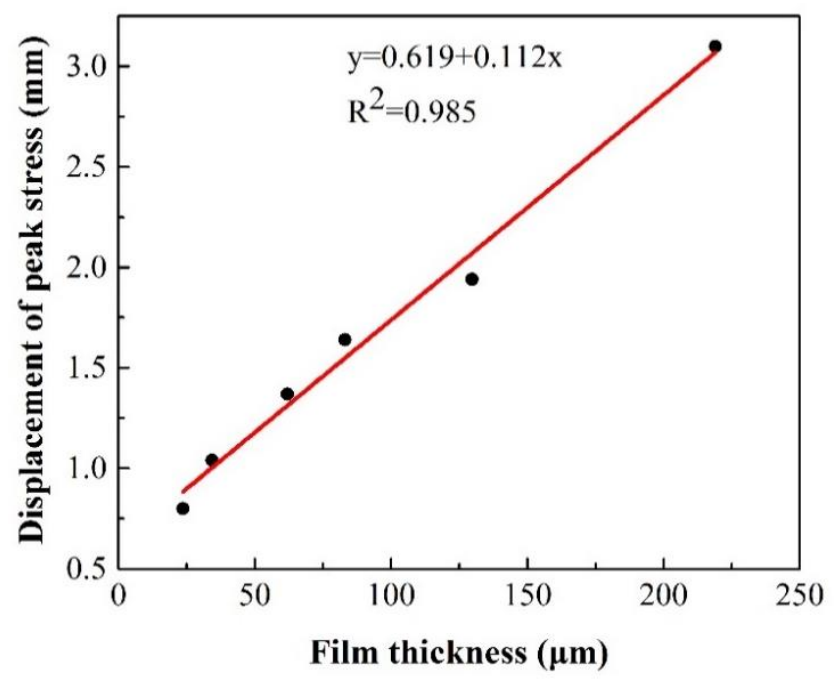

Fig.12. Displacement of peak stress vs. asphalt film thickness

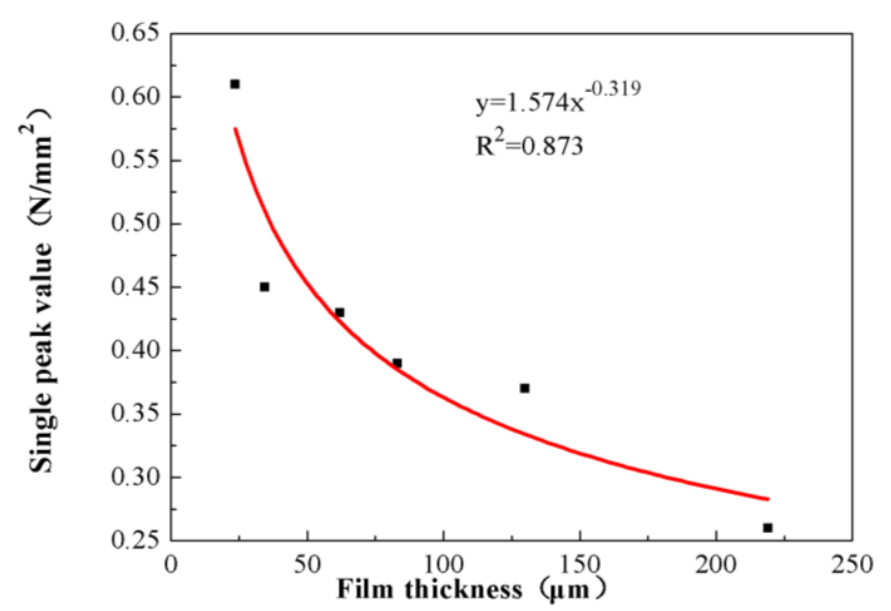

Fig.13. Peak stress vs. asphalt film thickness

\subsection{Structural characterization of asphalt film}

281 In order to explain the effects of asphalt film thickness on the shear response of asphaltaggregate interface, the structure of asphalt film between aggregates is analyzed based on the asphalt-aggregate adhesion mechanism. Fig. 14 shows the interaction between the asphalt and the aggregate surfaces. In the asphalt-aggregate interfacial system, the 


\begin{tabular}{ccccccc}
\hline Groups & G1 & G2 & G3 & G4 & G5 & G6 \\
\hline $\begin{array}{c}\text { Thickness of } \\
\text { asphalt film }(\mu \mathrm{m}) \\
\begin{array}{c}\text { Proportion of free } \\
\text { asphalt }(\%)\end{array}\end{array}$ & 219.00 & 129.81 & 83.16 & 62.00 & 34.36 & 23.61 \\
\hline
\end{tabular}

asphalt molecules can be chemisorbed on the surface of mineral aggregates. This chemisorption results in a redistribution of the components in asphalt film, forming a layer of adsorbed solvation film that is termed as structural asphalt (see Fig. 14). The structural asphalt film layer is relatively thin (about $10 \mu \mathrm{m}$ [31]). The asphalt outside the structural asphalt layer is referred to as the free asphalt, which maintains the initial cohesion of asphalt, as show in Fig. 14. When the aggregates are only bonded by the structural asphalt, where there is no free asphalt between two layers of the structural asphalt film, a greater cohesive force can be obtained. If there is a large amount of free asphalt between two layers of structural asphalt on aggregate surface, the cohesive force would become small. The asphalt film thickness determines the proportions of free asphalt and structural asphalt between the aggregates, which directly affects the failure behavior of the asphalt-aggregate interface.

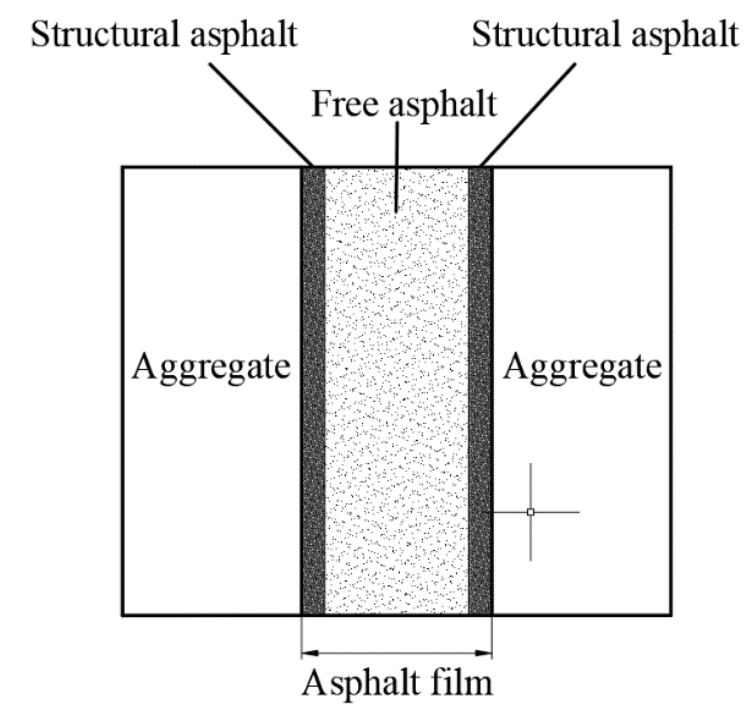

Fig.14. Structural characterization of asphalt film between aggregate surfaces

The free asphalt proportion in the aggregate-asphalt-aggregate sample can be calculated by Eq. (2).

$$
P f a=\frac{H-2 h}{H} \times 100 \%
$$

Where, $P$ fa is the free asphalt proportion, $H$ is the thickness of asphalt film in aggregateasphalt-aggregate sample, and $h$ is the thickness of structural asphalt that is $10 \mu \mathrm{m}$ in this study. Table 4 gives the proportion of free asphalt in different asphalt film thicknesses in the tests.

Table 4. Free asphalt proportion of aggregate-asphalt-aggregate samples 
which depends on the properties of the asphalt and the aggregate, asphalt film thickness and the loading rate [4]. In this study, the same asphalt and aggregate and the loading rate are used in the shear tests. Thus, the shear failure modes of the interface results from the asphalt film thickness in the aggregate-asphalt-aggregate system. The film thickness dominates the proportion of free asphalt in the film. The cohesive force of structural asphalt is greater than that of the free asphalt at $25^{\circ} \mathrm{C}$. The larger the free asphalt content, the worse the overall cohesive performance of asphalt film [32]. Thus, the film thickness can eventually affect the mechanical properties of the interface phase.

\subsection{Shear failure mechanism for single peak mode}

Based on the structural analysis of asphalt film with different thicknesses, the shear failure mechanism of the asphalt-aggregate interface is investigated. In the direct shear tests, results of the first group (G1) experiment show that, when the proportion of free asphalt in asphalt film with the thickness of $219.00 \mu \mathrm{m}$ is over $90.87 \%$, the failure of interface phase is the cohesive failure. The shear stress peak is minimum $0.26 \mathrm{MPa}$ and the displacement for the peak stress is maximum $3.10 \mathrm{~mm}$. Fig. 15 illustrates the thick interfacial states of the aggregate-asphalt-aggregate system before and after the shear loads are applied. In this case, the asphalt film in the interface phase is composed of a certain thickness of structural asphalt and a large amount of free asphalt. The interface phase has poor cohesive property due to the presence of a large amount of free asphalt. When the asphalt-aggregate interface is subjected to shear loads, the damage is more likely to initiate within the free asphalt (cohesive failure), as shown in Fig. 15. Thus, the stress-displacement curves are all single peak curves because of a single cohesive failure.

Results of the sixth group (G6) experiment show that, when the proportion of free asphalt in asphalt film is less than $15.29 \%$, the failure of interface phase could be the adhesion failure. The stress peak value is largest $0.61 \mathrm{MPa}$ and the corresponding displacement is minimal $0.8 \mathrm{~mm}$. Fig. 16 demonstrates the thin interfacial states of the aggregate-asphalt-aggregate system before and after the shear loads are applied. In this case, the asphalt film of aggregate-asphalt-aggregate interface is thinnest, mainly composed of structural asphalt with larger cohesive strength. When the asphaltaggregate interface is subjected to shear loads, the failure is more likely to occur on the contact surface of the asphalt and the aggregate, resulting in the adhesive failure, as shown in Fig. 14. Thus, the stress-displacement curves are all single peak modes due to a single adhesive failure.

\subsection{Shear failure mechanism for double peak mode}

In the second to fifth group (G2-G5) of experiments, both single peak and double peak modes of the stress-displacement curves occurs, which are different from the results of the first and sixth group (G1 and G6) of experiments with the single mode. When the molding loads increases from $10.37 \mathrm{kPa}$ to $179.76 \mathrm{kPa}$ in these shear tests, the thickness of the asphalt film between aggregates varies from $129.86 \mu \mathrm{m}$ to $34.36 \mu \mathrm{m}$. Within this thickness range, the adhesive and cohesive failure can occur simultaneously at the aggregate-asphalt-aggregate interfacial system. The cohesion within asphalt film and 

the adhesion at the asphalt-aggregate interface are prone to cause a slip phenomenon

351 [20]. Slippage plays the lubricating role in the interface failure, which makes the shear 352 stress be rapidly reduced. Thus, this slippage might be the cause of the double peak 353 curves.

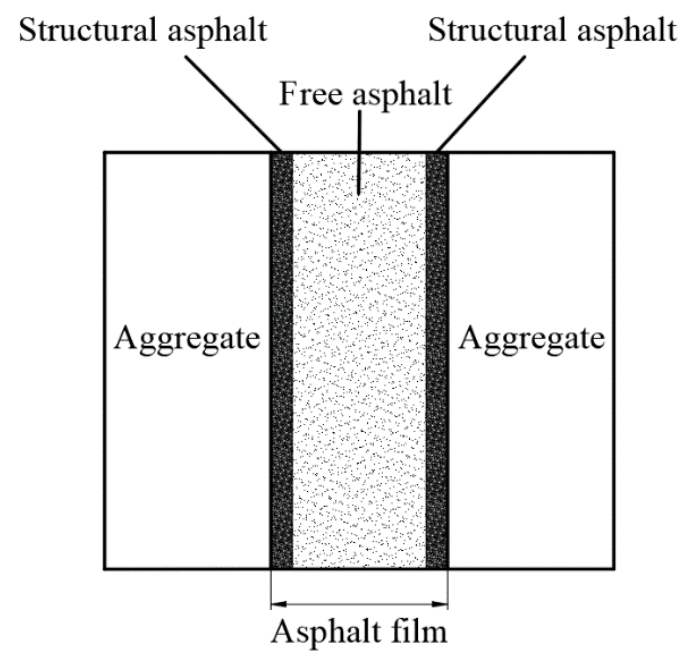

(a) Before shear loading

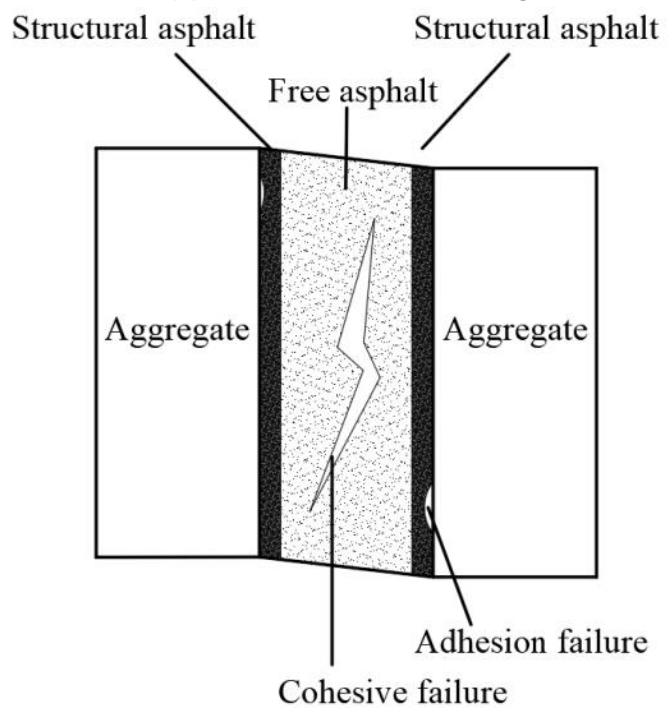

(b) After shear loading

Fig.15. Failure mechanism of thick asphalt film interface 


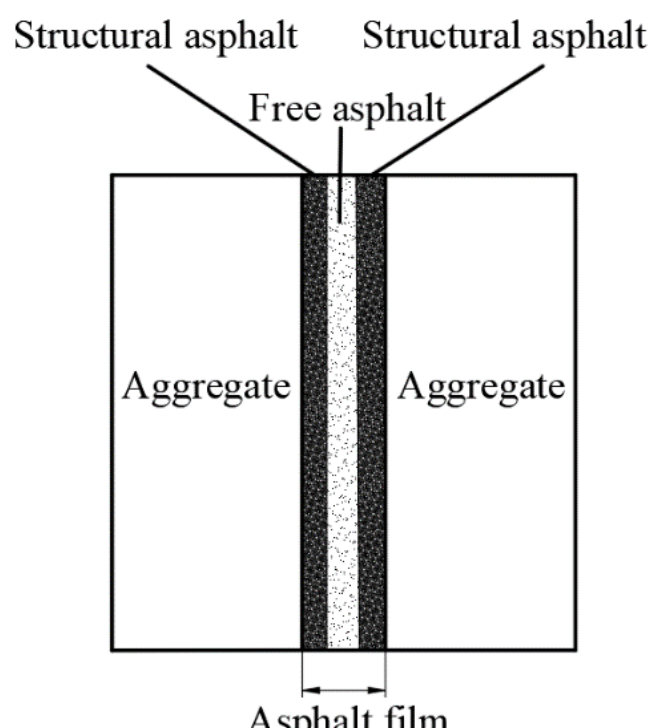

(a) Before shear loading

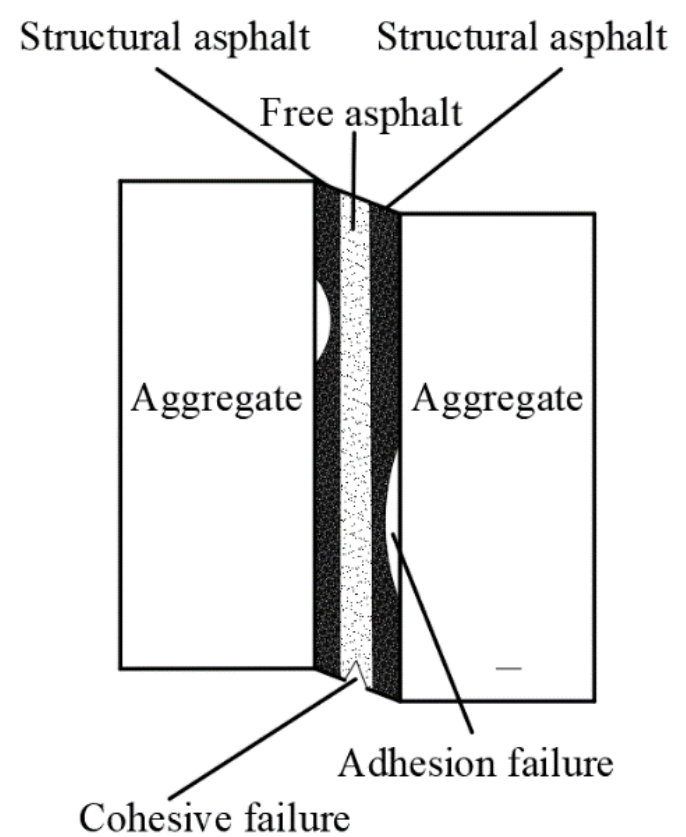

(b) After shear loading

Fig.16. Failure mechanism of thin asphalt film interface

In the view of the slip theory, there is a viscous fluid layer with a certain thickness at the junction of solid and fluid. The slip phenomenon can occur between the viscous fluid layer and the fluid [33, 34]. Some researchers have investigated the slip phenomenon. Vinogradova [35] proposed a Navier slip length model and found that the slip length is a fixed value under the same conditions. Granick, et al. [36] and Neto, et al. [37] inclined to the view that the slip length is related to the test conditions. In addition, Zhu, et al. [38] presented that the slip phenomenon only occurred when the stress reached a certain value. Based on these studies, it can be concluded that the slip phenomenon is generated under a certain condition and there is a randomness in the slip length. 
In this study, the shear tests are carried out in an environment of $25^{\circ} \mathrm{C}$. At this ambient temperature, the asphalt-aggregate interface does not meet the boundaryless slip condition during the shearing process, nor does it belong to complete slip. The shearing and slipping effects exist at the asphalt-aggregate interface at the same time. For the asphalt-aggregate interface, a layer of structural asphalt exists on the aggregate surface, which forms a viscous layer. The free asphalt in the asphalt film is regarded as the fluid. The viscosity difference between the structural asphalt and the free asphalt makes the asphalt-aggregate interface have the possibility of slippage.

When the asphalt film thickness between aggregates is $23.61 \mu \mathrm{m}$, the asphalt film is mainly composed of structural asphalt and the free asphalt content in the film is very low. Although the aggregate surfaces form a viscous layer, the slip cannot occur because of the low free asphalt content. When the asphalt film in the interface has a thickness of $219.00 \mu \mathrm{m}$, a large amount of free asphalt exists in the asphalt-aggregate interface. The interface failure is dominated by the cohesive failure with small stress and large strain. The shear stress does not reach the value where a slip can be initiated so the slip cannot occur due to the high free asphalt content. Therefore, there are no double peak curves in the first and sixth group (G1 and G6) of experiments.

When the asphalt film thickness between aggregates is within a range from $34 \mu \mathrm{m}$ to $129 \mu \mathrm{m}$, the structural asphalt and the free asphalt in the film have the probability of slipping under the shear loads. When the shear stress reaches a certain value, the slip phenomenon occurs. The slip plays a role of interface lubrication and the shear stress is reduced, resulting in a double peak curve. Therefore, in the failure process of the asphalt-aggregate interface, the slip between the structural asphalt and the free asphalt in asphalt film leads to the appearance of double peak curve. When the slip phenomenon does not appear, the stress-displacement curve of the shear test shows a single peak mode.

\section{Conclusions}

In this paper, the influence of asphalt film thickness on the mechanical failure mechanism of asphalt aggregate interface is investigated by aggregate-asphaltaggregate shear test, and the following conclusions are drawn:

(1) A molding method for test piece with expected thickness of asphalt film was developed. By adjusting the molding load, the test pieces with different asphalt film thickness could be obtained, and then the functional relationship between molding load and asphalt film thickness was established to realize the control of asphalt film thickness.

(2) The asphalt film thickness affects the probability of occurrence of double peak in the shear test on asphalt-aggregate-aggregate sandwich specimens. When the asphalt film thickness was between $34.36 \mu \mathrm{m}$ and $129.81 \mu \mathrm{m}$, double peak curves appeared. When the asphalt film thickness was $83 \mu \mathrm{m}$, the probability of occurrence of double peak curve was the largest.

(3) The asphalt film thickness affected the failure mechanism of asphalt-aggregate 
interface. When the asphalt film thickness was less than $23.61 \mu \mathrm{m}$, the failure of asphaltaggregate interface was mainly adhesion failure. When the asphalt film thickness was greater than $219 \mu \mathrm{m}$, the failure of asphalt-aggregate interface was mainly the cohesion failure. When the asphalt film thickness was $23.61 \mu \mathrm{m}$ to $219 \mu \mathrm{m}$, the failure mechanism of asphalt aggregate was the joint failure of adhesion failure and cohesive failure.

\section{Acknowledgements}

The authors would like to acknowledge the financial support from the National Nature Science Foundation of China (Grant No. 51978229), the Marie Skłodowska-Curie Individual Fellowships under EU's H2020 programme (Grant No. 789551), the Fundamental Research Funds for the Central Universities in China (Grant Nos. JZ2018HGTB0258), the National Nature Science Foundation of China (Grant No. 51408173), and the China Postdoctoral Science Foundation funded Project (Grant No. 2015M571928).

\section{References}

[1] L. Li, Y. Gao, and Y. Zhang. Crack length based healing characterisation of bitumen at different levels of cracking damage, J. Cleaner Prod. 258 (2020) 120709.

[2] Y. T. Choi, and Y. R. Kim. Implementation and verification of a mechanistic permanent deformation model (shift model) to predict rut depths of asphalt pavement, Road Mater. Pavement Des. 15( S1)(2014)195-218.

[3] L. Li, X. Huang, L. Wang, and C. Li. Integrated Experimental and Numerical Study on Permanent Deformation of Asphalt Pavement at Intersections. J. Mater. Civil Eng. 25(7) ( 2013) 907-912.

[4] Y. Zhang, X. Luo, R. Luo, and R. L. Lytton. Crack initiation in asphalt mixtures under external compressive loads. Constr. Build. Mater. 72(2014) 94-103.

[5] J. Zhang, G. Airey, and J. Grenfell. Experimental evaluation of cohesive and adhesive bond strength and fracture energy of bitumen-aggregate systems. Mater. Struct. 49 (2016) 2653-2667.

[6] Y. Gao, M. Dong, L. Li, L. Wang, and Z. Sun. Interface effects on the creep characteristics of asphalt concrete, Constr. Build. Mater. 96 (2015) 591-598.

[7] M. Dong, Y. Gao, L. Li, L. Wang, and Z. Sun. Viscoelastic micromechanical model for dynamic modulus prediction of asphalt concrete with interface effects, J. Cent. South Univ. 23 (2016) 926-933.

[8] Q. Xiao, C. Qian, and J. Xie. Study on the Test for Coupling Agent Improving the Performance of Asphalt Concrete and Oil-stone Interface, J. Southeast U:Nat. Sci. Ed. 34(4) ( 2004) 485-489.

[9] A. E. Alvarez, E. Ovalles, and S. Caro. Assessment of the Effect of Mineral Filler on Asphalt-Aggregate Interfaces Based on Thermodynamic Properties, Constr. Build. Mater. 28(1) (2012) 599-606.

[10]A Bhasin, and D. N Little. Characterization of Aggregate Surface Energy Using the Universal Sorption Device, J. Mater. Civ. Eng. 19(8) ( 2007) 634-641

[11]J Howson, E Masad, A Bhasin, D Little, and R Lytton. Comprehensive analysis of 
surface free energy of asphalts and aggregates and the effects of changes in $\mathrm{pH}$, Constr. Build. Mater. 25 (2011) 2554-2564.

[12]H. H, Yoon, and A. Tarrar. Effect of aggregate properties on stripping. Transp. Res. Record 11(71) (1988) 37-43.

[13]A. Mehrara, and A. Khodaii. A review of state of the art on stripping phenomenon in asphalt concrete, Constr. Build. Mater. 38(2013) 423-442.

[14] J. Schultz, and M. Nardin. Theories and mechanisms of adhesion. Handbook of Adhesive Technology, (1994)19-33.

[15]H. Chang, H. Zhang, Z. Jia, X. Li, W. Gao, and W. Wei. Wettability of coal pitch surface by aqueous solutions of cationic Gemini surfactants, Colloid. Surface. A 494(2016)59-64.

[16]Y. Tan, and M. Guo. Using surface free energy method to study the cohesion and adhesion of asphalt mastic, Constr. Build. Mater. 47(2013) 254-260.

[17]Y. Gao, Y. Zhang, F., T. Xu, and H. Wang. Impact of minerals and water on bitumen-mineral adhesion and debonding behaviours using molecular dynamics simulations, Constr. Build. Mater. 171 (2018) 214-222.

[18]Y. Gao, Y. Zhang, Y. Yang, J. Zhang, and F. Gu. Molecular dynamics investigation of interfacial adhesion between oxidised bitumen and mineral surfaces, Appl. Surf. Sci. 479(2019) 449-462.

[19]A. E. Alvarez, E. Ovalles, and A. E. Martin. Comparison of asphalt rubberaggregate and polymer modified asphalt-aggregate systems in terms of surface free energy and energy indices, Constr. Build. Mater. 35(2012) 385-392.

[20]M. Dong, Y. Hao, C. Zhang, L. Li, W. Sun, and C. Jin. Shear fracture energy of asphalt-aggregate systems and its application to predicting shear fatigue in asphalt mixtures, Int. J. Pavement Eng.21(2) (2020) 246-256.

[21]M. Dong, Y. Hao, C. Zhang, and L. Li. Failure mechanism analysis of asphaltaggregate systems subjected to direct shear loading, Mater. Struct. 50(5) (2017) 218.

[22] A. Noory, F. M. Nejad, and A. Khodaii. Effective parameters on interface failure in a geocomposite reinforced multilayered asphalt system, Road Mater. Pavement Des. 19(6) (2018) 1458-1475.

[23]M. Barman, J. M. Vandenbossche, and Z. Li. Influence of interface bond on the performance of bonded concrete overlays on asphalt pavements, J. Trans. Eng. B: Pavements 143(3) (2017) DOI: 10.1061/JPEODX.0000010.

[24]O. Portillo, and D. Cebon. Modeling Failure of Bitumen Films in Tension. Journal of Engineering Mechanics, J. Eng. Mech. 138(11) (2012) 1357-1371.

[25]G. G. Al-Khateeb. Conceptualizing the asphalt film thickness to investigate the superpave VMA criteria, Int. J. Pavement Eng. 19(11) (2018) 957-965.

[26] J. Yi, S. Shen, and D. Wang. Characterization of the Bonding Fracture Properties of the Asphalt-Aggregate System Using a Thin-Film Interface Test, J. Test. Eval. 44 (2016) 450-460.

[27]A. Cala, S. Caro, M. Lleras, Y. Rojas-Agramonte. Impact of the chemical composition of aggregates on the adhesion quality and durability of asphaltaggregate systems, Constr. Build. Mater. 216 (2019) 661-672. 
[28]B. Sengoz, and E. Agar. Effect of asphalt film thickness on the moisture sensitivity characteristics of hot-mix asphalt, Build. Environ. 42 (10) (2007) 3621-3628.

[29]B. Sengoz, and A. Topal. Minimum voids in mineral aggregate in hot-mix asphalt based on asphalt film thickness, Build. Environ. 42(10) (2007) 3629-3635.

[30]M.A. Elseifi, I. L. Al-Qadi, S. H. Yang, and S. H. Carpenter. Validity of asphalt binder film thickness concept in hot-mix asphalt, Transp. Res. Record, 2057 (2008) 37-45.

[31]Y.Q. Tan. Asphalt and asphalt mixture (in Chinese), Harbin: Harbin University of Technology Press (2007).

[32] S.C. Huang, J. F. Branthaver, R. E. Robertson, and S. S. Kim. Effect of Film Thickness on the Rheological Properties of Asphalts in Contact with Aggregate Surface. Trans Res Record, J Trans Res Board, 1638 (1998) 31-39.

[33]J. S. Ellis, and M. Thompson. Slip and coupling phenomena at the liquid-solid interface, Phys. Chem. Chem. Phy. 6(24) ( 2004) 4928-4938.

[34]D. Jing, and B. Bhushan. The coupling of surface charge and boundary slip at the solid-liquid interface and their combined effect on fluid drag: A review, J. Colloid Interf. Sci. 454 (2015) 152-179.

[35]O. I. Vinogradova. Drainage of a thin liquid film confined between hydrophobic surfaces, Langmuir 11(6) (1995) 2213-2220.

[36]S. Granick, Y. Zhu, and H. Lee. Slippery questions about complex fluids flowing past solids, Nat. Mater. 2(4) (2003) 221.

[37]C. Neto, V. S. J. Craig, and D. R. M. Williams. Evidence of shear-dependent boundary slip in Newtonian liquids, Eur. Phys. J. E 12(1) (2003) 71-74.

[38]Y. Zhu, and S. Granick. No-slip boundary condition switches to partial slip when fluid contains surfactant, Langmuir, 18(26) (2002) 10058-10063. 